J. Dairy Sci. 96:3621-3631

http://dx.doi.org/10.3168/jds.2012-5922

(C) American Dairy Science Association ${ }^{\circledR}, 2013$.

\title{
Metritis in dairy cows: Risk factors and reproductive performance
}

\author{
M. J. Giuliodori, ${ }^{\star}$ R. P. Magnasco,† D. Becu-Villalobos,† I. M. Lacau-Mengido,† C. A. Risco,§ \\ and R. L. de la Sota\# $\|^{1}$ \\ *Cátedra de Fisiología, Facultad de Ciencias Veterinarias - Universidad Nacional de La Plata (FCV-UNLP), La Plata, B1900AVW, Argentina \\ †Estudio Magnasco, Canals, Córdoba, X2650BXC, Argentina \\ łInstituto de Biología y Medicina Experimental - Consejo Nacional de Investigaciones Científicas y Técnicas (IByME - CONICET), Buenos Aires, \\ C1428ADN, Argentina \\ §Large Animal Clinical Sciences, College of Veterinary Medicine, University of Florida (LACS, CVM-UF), Gainesville 32611 \\ \#Cátedra y Servicio de Reproducción Animal, FCV-UNLP, La Plata, B1900AVW, Argentina \\ ॥CONICET, Buenos Aires, C1033AAJ, Argentina
}

\section{ABSTRACT}

The objectives of this study were to assess the risk factors for metritis, its effects on milk yield and on reproductive performance, and the efficacy of ceftiofur therapy in Holstein dairy cows. Cows $(\mathrm{n}=303)$ from a commercial dairy herd in Argentina were studied. Cows were scored for body condition, and blood samples were collected on $\mathrm{d}-14,7,21,31,41$, and 50 relative to parturition. Cows having a watery, purulent, or brown, and fetid vaginal discharge (VD) and rectal temperature $\leq 39.2^{\circ} \mathrm{C}$ were diagnosed as having clinical metritis, and those having a similar VD and rectal temperature $>39.2^{\circ} \mathrm{C}$ were diagnosed as having puerperal metritis. Both clinical and puerperal metritis cows were randomly assigned to control (no treatment) or ceftiofur group $(2.2 \mathrm{mg} / \mathrm{kg} \times 3$ consecutive days). Cure was declared if clear VD was observed at $21 \mathrm{~d}$ in milk (DIM). Blood samples were analyzed for nonesterified fatty acids, $\beta$-hydroxybutyrate, and blood urea nitrogen using commercial kits, and for insulin-like growth factor-1, insulin, and leptin by RIA. Data were analyzed with PROC MIXED, GENMOD, PHREG, and LIFETEST from SAS (SAS Institute Inc., Cary, NC). The risk for metritis increased with dystocia, retained fetal membranes, and dead calf [AOR (adjusted odds ratio) $=2.58,95 \%$ CI: $1.189-5.559]$, and as prepartum nonesterified fatty acids levels increased $(\mathrm{AOR}=1.001$, 95\% CI: 0.999-1.002). Conversely, risk decreased as prepartum insulin-like growth factor-1 increased (AOR $=0.65,95 \%$ CI: 0.349-1.219). Cows having either clinical or puerperal metritis produced less milk by 90 DIM than did healthy cows $(2,236 \pm 172$ vs. $2,367 \pm 77$ vs. $2,647 \pm 82 \mathrm{~kg}$, respectively). Cows with puerperal metritis had lower risk for pregnancy by 100 DIM (AOR $=0.189,95 \%$ CI: $0.070-0.479)$ and a lower hazard rate

Received July 9, 2012.

Accepted February 18, 2013.

${ }^{1}$ Corresponding author: dairydoc $82 @$ gmail.com for pregnancy by 150 DIM (hazard rate: $0.753,95 \%$ CI: 0.621-0.911), and took longer to get pregnant (129 vs. 111 vs. 109 d, for puerperal metritis, clinical metritis, and healthy cows, respectively). Ceftiofur treatment was not associated with cure rate or milk yield but was related to increased risk for pregnancy at timed artificial insemination $(\mathrm{AOR}=2.688,95 \%$ CI: $0.687-$ 10.832), and for lower risk of reproductive cull (AOR = 0.121, 95\% CI: 0.014-1.066). In conclusion, abnormal calving and negative energy balance are associated with increased risk for metritis. Metritis, especially puerperal metritis, correlates with reduced milk production and poor reproductive performance. Finally, the likelihood for having a normal VD (indicative of cure) increased $2.6 \%$ for every day of increase in postpartum time and was 2 times higher for cows with clinical metritis than for those with puerperal metritis.

Key words: dairy cow, puerperal metritis, risk factor, reproductive performance

\section{INTRODUCTION}

In postpartum dairy cows, uterine diseases such as metritis and endometritis affect a large proportion of the population and are associated with substantial productive losses (Fourichon et al., 1999, 2000). Despite the importance of uterine disease in the dairy system, case definitions were standardized only recently. Thus, cows having enlarged uterus, fetid watery red-brown vaginal discharge (VD), fever, and signs of systemic illness within 21 DIM are defined as having puerperal metritis, whereas cows having enlarged uterus and fetid watery red-brown VD without signs of systemic illness within 21 DIM are defined as having clinical metritis; and cows having pus in VD, 21 DIM or more, without systemic signs of illness are defined as having clinical endometritis (Sheldon et al., 2006). While there is no gold standard for the diagnosis of these uterine diseases, evaluation of VD is the most useful procedure, 
because pus in VD is correlated with pathogenic bacteria load in the uterus (LeBlanc et al., 2002; Williams et al., 2005). Among risk factors for metritis are calving problems (dystocia, twins, retained placenta, and stillbirth; Gröhn et al., 1990; Correa et al., 1993), low DMI (Urton et al., 2005; Huzzey et al., 2007), and high prepartum serum NEFA concentration (Dubuc et al., 2010; Ospina et al., 2010). The consensus is that cows with metritis require systemic antibiotic treatment because of severe illness and risk for death but criteria for assessing treatment success are inconsistent (LeBlanc, 2008). Treatments of choice include ceftiofur ( 1 to 2 $\mathrm{mg} / \mathrm{kg}$ i.m., $1 / \mathrm{d})$ or procaine penicillin $(21,000 \mathrm{IU} / \mathrm{kg}$ i.m., 2/d) for 3 to 5 d (Smith et al., 1998; Drillich et al., 2001; Chenault et al., 2004). The remission of fever is approximately $70 \%$ by 5 to $10 \mathrm{~d}$ after treatment, but elimination of fetid VD is much lower (Drillich et al., 2001; Chenault et al., 2004). Therefore, there is a lack of information about postpartum self-cure (because most studies have used positive controls) and about the efficacy of treatment for prevention of subsequent related diseases or for improvement of eventual productive and reproductive performance (LeBlanc, 2008).

The objectives of this study were to assess (1) the clinical and metabolic risk factors for metritis, (2) the use of rectal temperature and BCS as diagnostic tools for metritis, (3) the effects of metritis on reproductive performance, milk yield, and metabolic status, (4) the efficacy of ceftiofur therapy on cure rate, milk production, and reproductive performance, and (5) the selfcure rate during postpartum period.

\section{MATERIALS AND METHODS}

\section{Animals and Treatments}

The study was conducted in a commercial dairy herd $\left(32^{\circ} 49^{\prime} \mathrm{S}, 62^{\circ} 52^{\prime} \mathrm{W}\right.$, Argentina) with 1,600 Holstein cows with a milk yield of $8,500 \mathrm{~kg} / 305 \mathrm{~d}$, where autumn-calving cows $(\mathrm{n}=303)$ were enrolled. Ambient temperature and relative humidity were monitored at a weather station located $16 \mathrm{~km}$ from the farm. Average temperaturehumidity index (THI) during the study period (March to August) was $56.7 \pm 0.82$. Prepartum transition cows that were within 3 wk of expected calving date were maintained on dry lots, fed a low DCAD diet, and monitored for signs of calving by trained personnel through visual observation. After calving, cows were sent for 3 $\mathrm{d}$ to the fresh herd and kept on a dry lot. At 4 DIM, healthy cows were moved to a lactating herd kept in a dry lot and fed 4 times daily. Diets for both pre- and postpartum transition cows were a TMR formulated to meet or exceed the requirements of lactating dairy cows according to guidelines established by the NRC (2001).
Lactating dairy cows were milked 3 times a day (0400, 1200 , and $2000 \mathrm{~h}$ ). After a voluntary waiting period of $40 \mathrm{~d}$, healthy cows having either a clear normal or clear with flecks of pus vaginal discharge were estrous synchronized and received a timed artificial insemination (TAI) 50 DIM. Pregnancy was checked by palpation per rectum $35 \mathrm{~d}$ post-TAI. Calving history and milk yield were obtained from dairy records.

\section{Sampling}

We estimated a sample size of 300 cows to detect a 15-percentage-points reduction in metritis incidence (from $40 \%$ in control cows to $25 \%$ in ceftiofur-treated cows; Chenault et al., 2004). The sample size estimation was calculated with WinEpiscope 2.0, by using a 95\% CI and $80 \%$ of power (Thrusfield et al., 2001). A prevalence of metritis of $40 \%$ was obtained from the dairy farm records of the last $3 \mathrm{yr}$. Cows were scored for body condition (5-point scale; Edmonson et al., 1989; Ferguson et al., 1994) and were tail bled between 1600 and $1800 \mathrm{~h}$ on $14 \pm 3 \mathrm{~d}$ prepartum, and on $7,21,31$, 41 , and 50 DIM. Blood samples were collected in 10-mL polystyrene vials containing $20 \mathrm{mg}$ of $\mathrm{Na}_{2}$ EDTA and kept in an ice bath during sampling. Plasma was harvested within $2 \mathrm{~h}$ after sampling and stored at $-20^{\circ} \mathrm{C}$ until analysis. Rectal temperature was measured on 5,6 , and 7 DIM by inserting the glass thermometer (Franklin, Termómetros Argentinos S.A., Buenos Aires, Argentina; accuracy and resolution of $0.1^{\circ} \mathrm{C}$ between 32 and $43.9^{\circ} \mathrm{C}$ measured between 18 and $28^{\circ} \mathrm{C}$ ) at a $45^{\circ}$ angle approximately 8 to $10 \mathrm{~cm}$ into the rectum to ensure that the bulb made full contact with the rectal wall. Subsequently, a sample of VD was obtained with a gloved hand and observed by direct inspection on 5 to $7,21,31$, and 41 DIM (Williams et al., 2005). The following scale was used: VD-0 = normal clear discharge, VD-1 = clear discharge with pus flecks, VD-2 = mucopurulent not fetid discharge, and VD-3 = watery, purulent or brown-colored, and fetid discharge (adapted from Chenault et al., 2004).

\section{Diagnostic Criteria}

Abnormal calving included cows having dystocia (defined in a 3-point scale as follows: $1=$ no assistance, $2=$ slight to moderate assistance, and $3=$ extreme assistance or veterinary assistance, retention of placenta (fetal membranes not expelled by $24 \mathrm{~h}$ ), or delivering a dead calf. Metritis was defined as cows having VD-3 on 5 to 7 DIM independently of their rectal temperature (Sheldon et al., 2006). Clinical metritis was defined as cows having VD-3 and a rectal temperature $\leq 39.2^{\circ} \mathrm{C}$ on 5 to 7 DIM and puerperal metritis as cows having 
VD-3 and a rectal temperature $>39.2^{\circ} \mathrm{C}$ on 5 to 7 DIM (Smith et al., 1998). Clinical endometritis was defined as cows having VD-1, 2, or 3 between 21 and 41 DIM (Sheldon et al., 2006). Cows not becoming pregnant and diagnosed with persistent clinical endometritis (purulent and fetid vaginal discharge) together with those that aborted were categorized as reproductive culling.

\section{Ceftiofur Trial}

Cows having metritis (VD-3 on 5-7 DIM, independently of rectal temperature) were included in the ceftiofur trial and randomly allocated to the ceftiofur treatment group (ceftiofur hydrochloride, $2.2 \mathrm{mg} / \mathrm{kg}$ of BW i.m. for 3 consecutive days following the manufacturer's recommendation; Ceobiotic, Tecnofarm SRL, Buenos Aires, Argentina), or to the untreated control group. Cure rate was assessed by inspection of VD, as noted above, on 21 DIM. Cure was declared when cows had a clear, normal VD on 21 DIM.

\section{Laboratory Analysis}

Subsamples of cows were randomly obtained and their respective plasma samples were used for metabolite (cows, $\mathrm{n}=110$; samples, $\mathrm{n}=660$ ) and metabolic hormone (cows, $\mathrm{n}=50$; samples, $\mathrm{n}=300$ ) analyses.

Metabolites. Blood plasma samples were analyzed for NEFA, BHBA, and BUN using commercial kits (NEFA-HR(2), Wako Chemicals, Richmond, VA; Ranbut RB1007, Randox Laboratories, Antrim, UK; and Urea Color-2, Wiener Lab, Rosario, Argentina, respectively). Intraassay $\mathrm{CV}$ were $5.7,6.3$, and $6.5 \%$, respectively, and interassay CV were $7.1,7.6$, and $7.8 \%$, respectively. Metabolite concentrations were expressed in micromoles per liter $(\mu M)$ for NEFA and BHBA, and milligrams per deciliter for BUN.

Metabolic Hormones. Hormones were measured by RIA as previously described (Lacau-Mengido et al., 2000; Díaz-Torga et al., 2001; Becú-Villalobos et al., 2007). Briefly, the IGF-1 RIA was performed, after acidethanol extraction, with the IGF-1 antibody (UB2-495, Hormone Distribution Program of the National Institute of Diabetes and Digestive and Kidney Diseases, Bethesda, MD). The minimum detectable concentration was $0.33 \mathrm{n} M$, and intra- and interassay CV were 7.2 and $8.8 \%$, respectively. Insulin RIA was performed by using anti-bovine insulin antibody (Sigma, St. Louis, MO) and standard human insulin (Laboratorios Beta, Buenos Aires, Argentina). Minimum detectable concentration was $0.08 \mathrm{ng} / \mathrm{mL}$, and intra- and interassay $\mathrm{CV}$ were 6.8 and $8.9 \%$, respectively. Leptin RIA was performed by a double antibody method with ovine-specific antiserum (Delavaud et al., 2002) and recombinant bovine leptin
(DS Labs, Webster, TX; Becú-Villalobos et al., 2007). The minimum detectable concentration of leptin was $0.02 \mathrm{n} M$ and intra- and interassay $\mathrm{CV}$ were 6.7 and $9.0 \%$, respectively. Metabolic hormone concentrations were reported in nanograms per milliliter.

\section{Statistical Analysis}

Data are shown as least squares means \pm standard errors (LSM $\pm \mathrm{SE}$ ). Statistical significance was set at $P<0.05$, and a trend for significance was set at $P<$ 0.10 unless otherwise stated. The cow was considered the experimental unit.

Metritis and Reproduction. The risks for metritis, cure, and reproductive outcomes (e.g., pregnancy, culling) were analyzed with PROC GENMOD (SAS Institute, 2003) with binomial distributions and logit link functions. The logistic model for the clinical risk of metritis included the fixed effect of parity ( 1 vs. $\geq 2$ ), calving (normal vs. abnormal; abnormal calving included dystocia, retention of placenta, and dead calf), and their second-order interaction. The model for metabolic risk factors included the fixed effects of BCS, metabolites (NEFA, BHBA, and BUN), and metabolic hormones (IGF-1, insulin, and leptin) at $14 \pm 3 \mathrm{~d}$ prepartum. These predictor variables were included as continuous variables. The logistic model for the risk for cure at 21 DIM only included the fixed effect of ceftiofur (yes vs. no). Finally, the logistic model for the effect of metritis on reproductive outcomes included the fixed effect of parity ( 1 vs. $\geq 2$ ), calving (normal vs. abnormal), metritis (no vs. clinical vs. puerperal), clinical endometritis (no vs. yes), and their second-order interactions. Modeling was performed using a manual backward elimination method with an exclusion criterion set at $P>0.2$. Calving-to-conception and calving-to-culling intervals by 150 DIM were analyzed with PROC PHREG (SAS Institute, 2003). Cox proportional hazards regression models included the fixed effect of parity ( 1 vs. $\geq 2$ ), calving (normal vs. abnormal), metritis (no vs. clinical vs. puerperal), clinical endometritis (no vs. yes), and their second-order interactions. Modeling was performed using a manual backward elimination method with an exclusion criteria set at $P>0.2$. Time intervals (median $\pm 95 \% \mathrm{CI}$ ) for days open and survival function estimates were obtained from PROC LIFETEST (SAS Institute, 2003).

Diagnostic Tools. Body condition score and rectal temperature as diagnostic tools for metritis were analyzed with receiver operator characteristics (ROC) curves by using Sigmaplot 10.0 (Systat, 2006). Vaginal discharge with fetid odor (VD-3) was used as a gold standard for metritis in the ROC analysis. Sensitivity (Se) was the proportion of animals diagnosed with 
metritis (having VD-3) that were above a given threshold, and specificity (Sp) was the proportion of animals diagnosed as without metritis (not having VD-3) that were below a given threshold (Greiner et al., 2000). The critical threshold was the point on the ROC curve that had the highest combined Se and Sp. Interpretation of critical threshold was based on the area under the curve. Likelihood ratio positive $(\mathbf{L R}+)$ was the probability that a test result at or above the threshold would be more likely to come from an animal with metritis (having VD-3).

Milk Yield and Metabolic Status. Milk, metabolites and metabolic hormones were analyzed with PROC MIXED (SAS Institute, 2003) as repeated measures. The model for milk yield included the random effect of the cow and the fixed effects of time $(-14 \pm 3$ vs. 7 vs. 21 vs. 31 vs. 41 vs. $50 \mathrm{~d}$ relative to parturition), parity (1 vs. $\geq 2$ ), calving (normal vs. abnormal), metritis (no vs. clinical vs. puerperal), clinical endometritis (no vs. yes), and their second-order interactions. The model for the effect of ceftiofur on milk yield included the random effect of the cow and the fixed effects of time $(-14 \pm 3$ vs. 7 vs. 21 vs. 31 vs. 41 vs. $50 \mathrm{~d}$ related to parturition), ceftiofur (no vs. yes), and their secondorder interaction. The model for metabolites and metabolic hormones included the random effect of the cow and the fixed effects of time $(-14 \pm 3$ vs. 7 vs. 21 vs. 31 vs. 41 vs. $50 \mathrm{~d}$ related to parturition), metritis (no vs. yes), clinical endometritis (no vs. yes), and their second-order interactions. The covariance structure having the smallest Akaike information criterion and Schwarz's Bayesian criterion was used (Littell et al., 2002). A polynomial contrast was used to test the linear and quadratic effects of time on response variables, and another contrast was used to compare prepartum versus postpartum values (for metabolites and metabolic hormones). The effect of time was removed from the models used to analyze milk yield by 90 DIM.

Vaginal Discharge. Cows diagnosed with metritis were used in this analysis, and their data on vaginal discharges were analyzed with PROC GENMOD (SAS Institute, 2003) by using a multinomial distribution (i.e., VD-0, 1, 2, and 3) and a cumulative logit link function. This repeated multinomial model included the fixed effect of time (21,31, and 41 DIM), parity (1 vs. $\geq 2$ ), calving (normal vs. abnormal), metritis (clinical vs. puerperal), ceftiofur (yes vs. no), and their second-order interactions. Modeling was performed using a manual backward elimination method with an exclusion criteria set at $P>0.2$.

\section{RESULTS}

A total of 303 cows were enrolled in the study period, and 19 cows were not included because they were culled for mastitis $(\mathrm{n}=10)$, lameness $(\mathrm{n}=6)$, or pneumonia $(\mathrm{n}=3)$ before the recheck for cure (VD evaluation) on $21 \mathrm{~d}$ postpartum. Therefore, 303 cows were used in the incidence rate analysis and 284 were used in the remainder of the analyses.

\section{Incidence of and Risk Factors for Metritis}

Incidence of puerperal metritis was $29.7 \%(90 / 303)$ and of clinical metritis was 9.6\% (29/303). Multiparous cows had lower odds for metritis than primiparous herdmates [adjusted odds ratio $(\mathbf{A O R})=0.646,95 \% \mathrm{CI}$ : 0.371-1.125; Table 1). Cows with abnormal calving had higher odds than herdmates with normal calving (AOR $=2.576,95 \%$ CI: 1.189-5.559; Table 1). High levels of prepartum NEFA were associated with increased risk $(\mathrm{AOR}=1.001,95 \% \mathrm{CI}: 0.999-1.002$; Table 1$)$, whereas high levels of prepartum IGF-1 $(\mathrm{AOR}=0.652,95 \% \mathrm{CI}$ : 0.349-1.219; Table 1) were related to reduced risk for metritis. Prepartum NEFA ( $=110$ cows) had a ROC area of $0.52 \pm 0.07(P=0.77)$ and a cut-off of 431 $\mu M(\mathrm{Se}=0.57, \mathrm{Sp}=0.63$, and $\mathrm{LR}+=1.51)$, whereas prepartum IGF-1 ( $\mathrm{n}=50$ cows) had a ROC area of $0.56 \pm 0.12(P=0.63)$ and a cut-off of $286 \mathrm{ng} / \mathrm{L}(\mathrm{Se}=$ $0.33, \mathrm{Sp}=0.93$, and $\mathrm{LR}+=4.99)$.

\section{Diagnostic Tools for Metritis}

Rectal temperature at the time of metritis diagnosis (7 DIM, $\mathrm{n}=303$ cows) had a ROC area of $0.604 \pm$ $0.036(P=0.003)$ and a cut-off of $39.2^{\circ} \mathrm{C}(\mathrm{Se}=0.566$, $\mathrm{Sp}=0.638$, and LR $+=1.567)$, whereas BCS (7 DIM, $\mathrm{n}=303$ cows $)$ had a ROC area of $0.636 \pm 0.029(P<$ $0.001)$ and a cut-off of $2.6(\mathrm{Se}=0.504, \mathrm{Sp}=0.706$, and $\mathrm{LR}+=1.718)$.

\section{Metritis and Reproduction}

Pregnancy rate by 100 DIM was affected by metritis $(P<0.001)$, with cows having puerperal metritis showing lower odds than healthy herdmates $(\mathrm{AOR}=0.219$, 95\% CI: 0.095-0.502), whereas cows with clinical metritis had similar odds to healthy cows $(\mathrm{AOR}=0.984$, 95\% CI: $0.376-2.577)$. Nonpregnancy rate by 200 DIM was affected by metritis $(P=0.095)$, with puerperal metritis cows having higher odds than healthy herdmates (AOR $=2.096,95 \%$ CI: 0.968-4.537) and clinical metritis cows having similar odds to healthy herdmates $(\mathrm{AOR}=0.599,95 \%$ CI: 0.129-2.779). The hazard for pregnancy per day at risk was affected by metritis $(P$ $=0.005)$, with cows having puerperal metritis showing a lower hazard rate than cows with clinical metritis or healthy herdmates (hazard rate $=0.753,95 \%$ CI: $0.621-0.911 ; P=0.014)$. Cows with puerperal metritis 
Table 1. Clinical and metabolic risk factors for metritis in Holstein dairy cows (parity, calving, and BCS, $\mathrm{n}=$ 303 ; metabolites, $\mathrm{n}=110$; hormones, $\mathrm{n}=50$ )

\begin{tabular}{|c|c|c|c|c|c|}
\hline \multirow[b]{2}{*}{ Risk factor } & \multicolumn{2}{|c|}{ Incidence } & \multicolumn{3}{|c|}{ Risk for metritis $^{1}$} \\
\hline & $\%$ & No./total & $\begin{array}{l}\text { Adjusted } \\
\text { odds ratio }\end{array}$ & $95 \%$ CI & $P$-value \\
\hline \multicolumn{6}{|c|}{ Clinical risk factors } \\
\hline \multicolumn{5}{|l|}{ Parity } & \multirow[t]{3}{*}{0.08} \\
\hline Primiparous & 48.9 & $44 / 90$ & Referent & & \\
\hline Multiparous & 35.2 & $75 / 213$ & 0.646 & $0.371-1.125$ & \\
\hline \multicolumn{5}{|l|}{ Calving } & \multirow{3}{*}{0.008} \\
\hline Normal & 34.6 & $90 / 260$ & Referent & & \\
\hline Abnormal & 65.1 & $28 / 43$ & 2.576 & $1.189-5.559$ & \\
\hline \multicolumn{6}{|c|}{ Metabolic risk factors $^{2}$} \\
\hline $\mathrm{NEFA}^{3}$ & - & 110 & 1.001 & $0.999-1.002$ & 0.18 \\
\hline IGF- $1^{4}$ & - & 50 & 0.652 & $0.349-1.219$ & 0.14 \\
\hline
\end{tabular}

had longer calving to conception interval (median $=$ 141.0, 95\% CI: 120.0-150.0) than cows having clinical metritis (median $=120.0,95 \%$ CI: $71.0-145.0$ ) or being healthy (median $=104.5,95 \%$ CI: 94.0-121.0, log-rank test $=8.33, \mathrm{df}=2, P=0.015$; Figure 1$)$.

\section{Metritis and Milk Yield}

Time by parity affected milk yield $(P<0.001)$, with multiparous cows producing more milk than primiparous herdmates from early to mid lactation and less milk than primiparous cows at the end of lactation. Time by metritis also affected milk yield $(P<0.001$, Figure 2), given that cows having (clinical and puerperal) metritis produced less milk than healthy herdmates during early lactation, whereas they produced more milk than healthy cows during late lactation (Figure 2). The remaining second-order interactions had no effect $(P>0.1)$.

Multiparous cows produced more milk by 90 DIM than primiparous herdmates (LSM \pm SE: 2,640.97 \pm 77.36 vs. $2,191.94 \pm 88.19 \mathrm{~kg} ; P<0.001)$. The healthy cows had higher production by 90 DIM than both the clinical metritis and puerperal metritis cows $(2,646.56$ \pm 82.10 vs. $2,235.62 \pm 172.11$ vs. $2,367.20 \pm 77.45 \mathrm{~kg}$, respectively; $P=0.009$ ). Interactions had no effect on milk yield by 90 DIM $(P>0.10)$.

\section{Metritis and Metabolic Status}

Cows with metritis had lower BCS than healthy herdmates $(2.58 \pm 0.02$ vs. $2.67 \pm 0.02 ; P=0.004)$. Time by metritis had an effect on NEFA, BHBA, BUN, and IGF-1 levels $(P=0.022,0.009,0.010$, and 0.007, respectively; Table 2, Figure 3). Metritis had no effect on insulin $(P=0.85)$ or on leptin $(P=0.35$; Table 2$)$.

\section{Ceftiofur and Reproduction}

Ceftiofur had no effect on cure at 21 DIM: the percentage of cured cows was similar for treated and untreated control cows [14\% (8/56) and 16\% (7/44), respectively; $P>0.10]$. Ceftiofur-treated cows had greater odds for

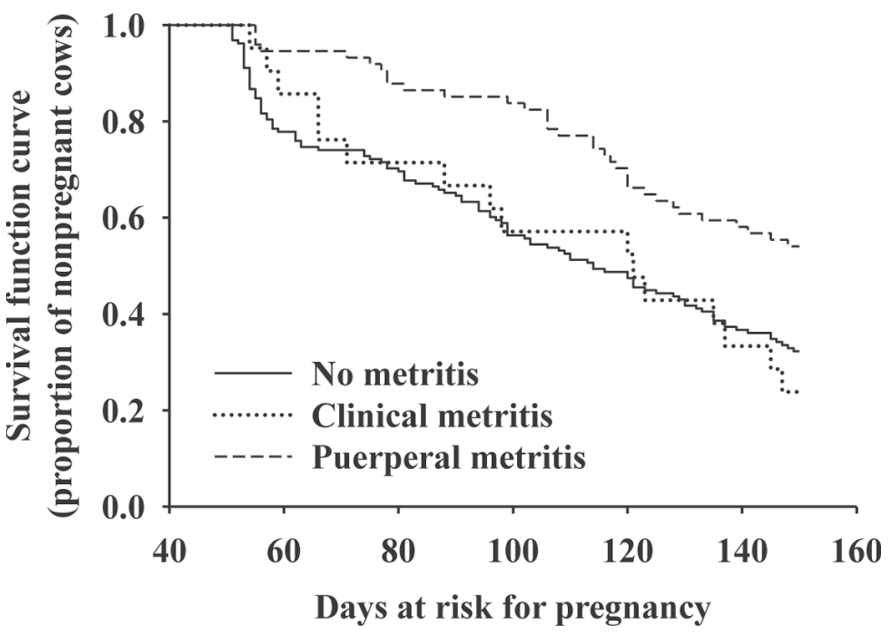

Figure 1. Survival function curves of calving to conception intervals by 150 DIM in Holstein dairy cows $(\mathrm{n}=303)$. Clinical metritis was defined as cows having watery, purulent, or brown, and fetid vaginal discharge with a rectal temperature $<39.2^{\circ} \mathrm{C}$; puerperal metritis was defined as cows having watery, purulent, or brown, and fetid vaginal discharge with a rectal temperature $\geq 39.2^{\circ} \mathrm{C}$ at 5 to $7 \mathrm{DIM}$. Cows with puerperal metritis had longer calving to conception intervals by $150 \mathrm{~d}$ (median $=141.0,95 \%$ CI: $120.0-150.0)$ than cows with clinical metritis $($ median $=120.0,71.0$ to 145.0$)$ and healthy herdmates $($ median $=$ 104.5, 95\% CI: 94.0 to $121.0, \log$-rank test $=8.33, \mathrm{df}=2 ; P=0.015$ ). 


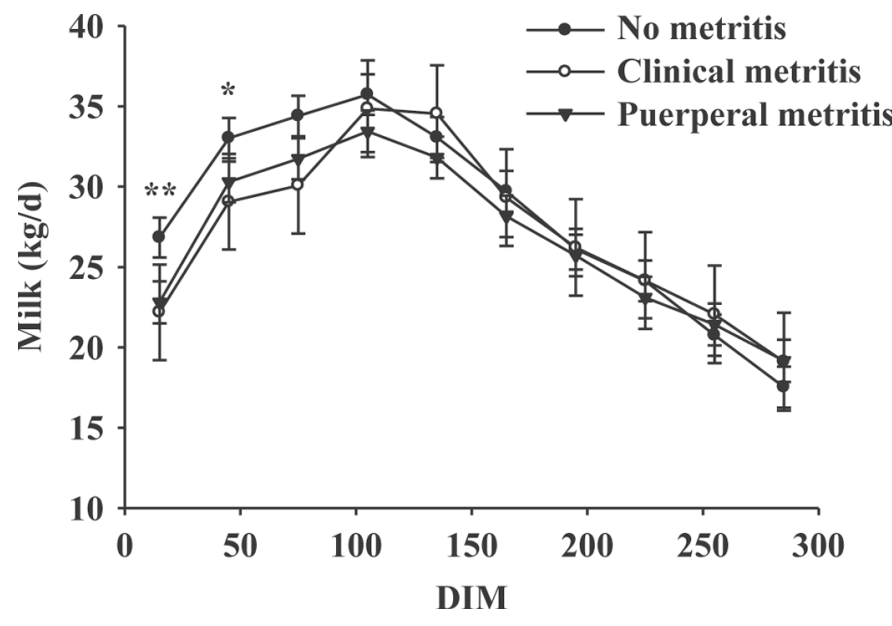

Figure 2. Mixed model effects on milk yield $(\mathrm{kg} / \mathrm{d})$ in Holstein dairy cows with clinical metritis, puerperal metritis, or no metritis $(\mathrm{n}=303)$. Clinical metritis was defined as cows having watery, purulent, or brown, and fetid vaginal discharge with a rectal temperature $<39.2^{\circ} \mathrm{C}$; puerperal metritis was defined as cows having watery, purulent, or brown, and fetid vaginal discharge with a rectal temperature $\geq 39.2^{\circ} \mathrm{C}$ at 5 to 7 DIM. There was a time by metritis effect on milk yield $(P<0.001) .{ }^{*} P<0.05,{ }^{* *} P<0.01$.

TAI and for pregnancy at TAI than control cows (AOR $=2.126,95 \%$ CI: 0.983-4.597, $P=0.055$, and AOR $=$ $2.688,95 \%$ CI: $0.667-10.832, P=0.14$, respectively). Ceftiofur also reduced reproductive culling from $13.6 \%$ $(6 / 44)$ to $1.8 \%(1 / 56)$. Thus, treated cows showed much lower odds for culling than control cows $(\mathrm{AOR}=0.121$, 95\% CI: $0.014-1.066 ; P=0.057)$.

\section{Ceftiofur and Milk Yield}

Ceftiofur had no effect on milk yield $(26.78 \pm 0.75$ vs. $26.41 \pm 0.72 \mathrm{~kg} / \mathrm{d} ; P=0.72$, for control and treated cows) or on milk produced by 90 DIM $(2,287.37 \pm$ 72.98 vs. $2,418.23 \pm 72.98 \mathrm{~kg} ; P=0.21$, for control and treated cows).

\section{Vaginal Discharge}

The evolution of VD during postpartum period is shown in Figure 4. The likelihood for having a clear, normal VD increased with time during postpartum $(\mathrm{AOR}=1.114,95 \% \mathrm{CI}=1.084-1.145 ; P<0.001)$. Hence, the risk for cure increased $11 \%$ per day during postpartum [(AOR - 1) $\times 100$ was used to transform AOR into percentage; Allison, 1999]. As the AOR for time (i.e., day) seemed to be misleading (i.e., $11 \%$ increase in the likelihood for normal VD per 1-d of increase in time during postpartum), the following equation: $\beta \times p_{i}\left(1-p_{i}\right)$ was used to address this concern (Allison, 1999), where $\beta$ is the regression coefficient for day $[0.1079(95 \% \mathrm{CI}=0.0808-0.1351)]$ and $p_{i}$ is the probability for normal VD (0.7604). The corrected change in probability for normal VD was $0.020(0.015$ to 0.025$)$ per 1-d increase during postpartum (between 7 and 41 DIM). In addition, the risk for normal VD was higher for cows with clinical metritis than for those having puerperal metritis $(\mathrm{AOR}=1.956,95 \% \mathrm{CI}$ : $1.151-3.324 ; P=0.013)$. The remaining predictors and their second-order interactions had no effect $(P>0.1)$.

\section{DISCUSSION}

The objectives of the study were to assess the risk factors for metritis; the effects of metritis on milk, reproductive performance, and metabolic status; and finally, the efficacy of ceftiofur therapy on cure rate, milk, and reproductive performance. The observed prevalence of metritis in this herd was within the range of reported data (Fourichon et al., 1999, 2000; Mejía and Lacau-Mengido, 2004).

\section{Risk Factors}

Our main findings were that primiparous cows, cows with abnormal calving, and cows in poor energy bal-

Table 2. Effect of metritis on the metabolic status in Holstein dairy cows

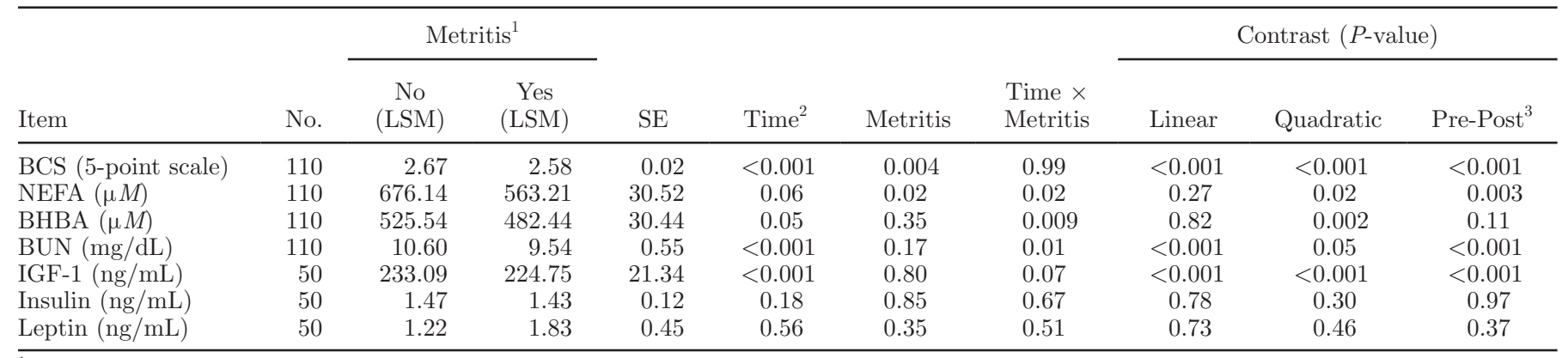

${ }^{1}$ Metritis was diagnosed in cows having watery, purulent, or brown, and fetid vaginal discharge 5 to 7 DIM.

${ }^{2}$ Time $=$ days related to parturition $(\mathrm{d}-14,6,21,31,41$, and 50$)$.

${ }^{3}$ Pre-Post $=$ prepartum versus postpartum. 


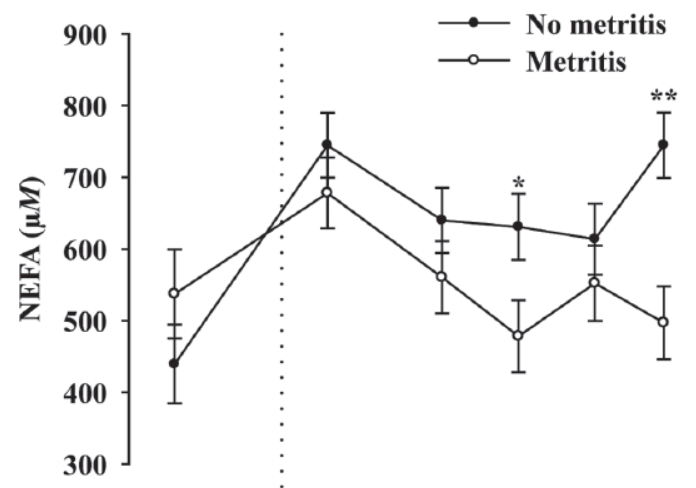

ance during prepartum (i.e., high NEFA and low IGF1) have increased risk for metritis. This is in agreement with previous studies (Gröhn et al., 1990; Correa et al., 1993; Kaneene and Miller, 1995; Dubuc et al., 2011). Primiparous cows have greater risk for metritis than multiparous herdmates because of a greater need for calving assistance (Bruun et al., 2002; Bell and Roberts, 2007; Ghavi Hossein-Zadeh and Ardalan, 2011). Abnormal calving usually requires human intervention, which increases the likelihood for bacterial contamination and uterine lesions, both leading to the development of metritis (Kaneene and Miller 1995; Sheldon and Dobson, 2004). In addition, our finding that high prepartum NEFA increases the risk for metritis supports 2 recently published studies (Ospina et al., 2010; Dubuc et al., 2011). These researchers suggested NEFA thresholds of $300 \mu M$ (Ospina et al., 2010) and 600 $\mu M$ (Dubuc et al., 2011) for predicting metritis, and we found a cut-off lying between (prepartum NEFA of $431 \mu M)$. We also found that high prepartum IGF-1 reduces the risk for metritis, and to our knowledge, this is the first report for an effect of IGF-1 on the risk for metritis. In short, our findings and those previously reported provide clear evidence that negative energy balance plays a key role in the development of metritis.

\section{Diagnostic Tools}

According to Swets (1988), a diagnostic test is accurate if the ROC area is 0.5 to 0.7 . Hence, the cut-off values obtained in this study for rectal temperature and BCS (ROC areas $\sim 0.6$ ) would be accurate diagnostic tools for metritis. Because many other diseases, such as mastitis, could increase rectal temperature, rectal temperature would be useful for the diagnosis but not diagnostic in itself. The same happens with BCS, given that many situations can lead to low BCS. Therefore, BCS would be useful for the diagnosis but not diagnostic in itself. Our cut-off value for temperature $\left(39.2^{\circ} \mathrm{C}\right)$ was lower than that of $39.5^{\circ} \mathrm{C}$ originally reported by Drillich et al. (2001) and recently suggested for the case definition by Sheldon et al. (2006). Whereas the cut-off of $39.5^{\circ} \mathrm{C}$ reported by Drillich et al. (2001) was arbitrarily set, the cut-off of $39.2^{\circ} \mathrm{C}$ in this study was obtained using a ROC analysis. In fact, most of previous studies have arbitrarily set the cut-off rectal temperature for diagnosis of metritis in early postpartum (Smith et al., 1998; Drillich et al., 2001, 2007; Chenault et al., 2004; Benzaquen et al., 2007), with the exception of one study where the cut-off was set at the $75 \%$ quartile (Sheldon and Dobson, 2004). A recent study by Wenz et al. (2011) reported that the rectal temperature of cows with metritis peaked on the day of diagnosis at $39.6 \pm 0.1^{\circ} \mathrm{C}$ and was $0.8^{\circ} \mathrm{C}$ higher than ing watery, purulent, or brown, and fetid vaginal discharge 5 to $7 \mathrm{~d}$ in milk. There was a time (day) by metritis effect on NEFA, BHBA, BUN, and IGF- 1 levels $(P=0.022,0.009,0.010$, and 0.007 , respectively). ${ }^{*} P<0.05,{ }^{* *} P<0.01$. 


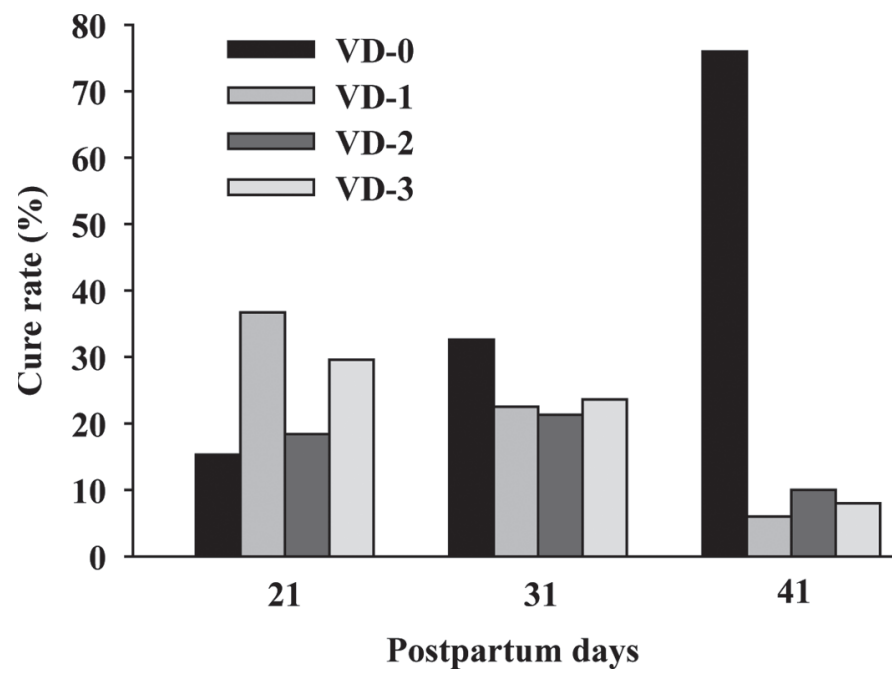

Figure 4. Cure rate between 21 and 41 postpartum days in Holstein dairy cows with metritis $(\mathrm{n}=119)$. Metritis was defined as a cow having watery, purulent, or brown, and fetid vaginal discharge at 5 to 7 DIM. VD-0 = normal, clear vaginal discharge; VD-1 = clear vaginal discharge with flecks of pus; VD-2 = muco-purulent non-fetid vaginal discharge; and VD-3 = watery, purulent, or brown, and fetid vaginal discharge. A multinomial cumulative logit model showed that time (postpartum day) had an effect on the likelihood for having a VD-0 ( $P$ $<0.001$ ), and that the probability for VD-0 increased $2.0 \%$ (1.5 to 2.5 ) per every $1 \mathrm{~d}$ of increase during postpartum.

that of parity-matched healthy cows during the first 10 DIM. Although only $2.5 \%$ of normal cows compared with $34 \%$ of cows with mastitis, metritis, or pneumonia had rectal temperature $>39.5^{\circ} \mathrm{C}$ (mean $+2 \mathrm{SD}$; Wenz et al., 2011), no reference was made to the percentage of cows with mastitis, metritis, or pneumonia that had rectal temperature $\leq 39.5^{\circ} \mathrm{C}$ or to changes in this percentage when the cut-off was increased or decreased. When the cut-off point is increased, the number of cows with fever that are actually healthy is reduced (type I error), but the number of cows with no fever that are actually diseased is increased (type II error; Kristula et al., 2001). Using ROC curves allows us to maximize sensitivity and specificity for a given cut-off of rectal temperature, avoiding treating too many healthy animals or not treating too many diseased animals.

Several factors such as operator, thermometer, penetration depth, and defecation may affect repeatability of rectal temperature measurement in dairy cows in early postpartum (Burfeind et al., 2010). In addition, Wenz et al. (2011) reported diurnal and seasonal variations in rectal temperature. The present study was done between May and August (fall and winter in the Southern Hemisphere). During that time of the year, the average THI was $56.5 \pm 0.85$. A reduction in milk yield as an indicator of cow discomfort starts when the THI is >72 (Igono et al., 1992); therefore, we would expect no effect of ambient temperature and humidity on rectal temperature measurement made in this study.

Regarding BCS, the cut-off of 2.6 reported here is, to our knowledge, the first reported cut-off of BCS for metritis. Finally, the limiting factor regarding the usefulness of rectal temperature and BCS as diagnostic tools for metritis is their low sensitivity ( 0.57 and 0.50 , respectively).

\section{Metritis and Reproduction}

Metritis, especially puerperal metritis, has a negative effect on reproductive performance (i.e., increased calving to conception interval). To our knowledge, this is the first study to compare the effect of clinical versus puerperal metritis, and the first to show that puerperal metritis has a much greater negative effect on production outcomes than clinical metritis. Fourichon et al. (2000) reviewed some studies and found impaired reproduction in cows with metritis. The negative effects of metritis could affect fertility in many ways: first, through a delay in the return to cyclicity after parturition (Mateus et al., 2002; Sheldon et al., 2002); second, through a clear disruption of the uterine environment (BonDurant, 1999; Sheldon and Dobson, 2004); and third, through an impairment of embryo development (Soto et al., 2003).

\section{Metritis and Milk Yield}

Clinical and puerperal metritis both have negative effects on peak milk yield. This is in agreement with previous reports that found lower milk production during early lactation in cows with metritis (Rajala and Grohn, 1998; Bell and Roberts, 2007; Dubuc et al., 2011; Wittrock et al., 2011). One reason for this effect could be that reduced feed intake in affected cows decreases the energy available for milk synthesis (Bell and Roberts, 2007; Wittrock et al., 2011). In fact, that reduced intake has been detected even before parturition (Urton et al., 2005; Huzzey et al., 2007).

\section{Metritis and Metabolic Status}

In the current study, cows with metritis had lower BCS than healthy herdmates and we found a metritis by time interaction on NEFA and BHBA concentrations. Cows with metritis have higher BHBA concentrations than healthy cows immediately after parturition, but later on in lactation (31 to 41 DIM) they have lower levels than normal herdmates. Therefore, cows with metritis would have a deeper negative energy balance around parturition, probably caused by low DMI prepartum (Urton et al., 2005; Huzzey et al., 2007). 
Then, as lactation progresses, healthy cows would have a deeper negative energy balance than cows with metritis because of the heavier demands imposed by the udder to support their higher milk production in early lactation.

\section{Ceftiofur}

Ceftiofur did not affect the cure of metritis or peak milk production. Ceftiofur increased the risk for pregnancy at TAI and reduced the risk for reproductive culling. The usefulness of ceftiofur therapy for the treatment of metritis has been studied (Smith et al., 1998; Drillich et al., 2001; Zhou et al., 2001; Chenault et al., 2004). Some works included positive controls (Smith et al., 1998; Drillich et al., 2001), whereas others used negative controls (Zhou et al., 2001; Chenault et al., 2004). In addition, most studies used body temperature (i.e., $<39.5^{\circ} \mathrm{C}$ ) to define a successful therapy; that is, when temperature returned to within normal range, animals were declared cured (Smith et al., 1998; Drillich et al., 2001; Zhou et al., 2001) even though many of them were still having a fetid VD (Drillich et al., 2001). As a result, rectal temperature as the only criterion for cure may overestimate the response to therapy (Chenault et al., 2004). Considering normal temperature and non-fetid VD as criteria for cure, the reported cure rates (14 d after initial treatment) are $62 \%$ for control cows, $65 \%$ for cows treated with $1.1 \mathrm{mg}$ of ceftiofur $/ \mathrm{kg}$ of BW, and $77 \%$ for those receiving 2.2 $\mathrm{mg}$ of ceftiofur/ $\mathrm{kg}$ of BW (Chenault et al., 2004). In our cows, 14 to $16 \mathrm{~d}$ after initial treatment, $70 \%$ of control and $68 \%$ of ceftiofur-treated cows had a non-fetid VD. Therefore, our results were similar to those of Chenault et al. (2004). Even more importantly, the efficacy of the ceftiofur treatment, based on production interest variables such as pregnancy rate at TAI or calving to conception interval, has not previously been reported. Only one study (using positive controls) reported no effect of treatment on measures of reproductive performance such as pregnancy rate at first AI, calving to conception interval, and culling rate (Drillich et al., 2001). In our study, ceftiofur tended to increase the risk for pregnancy at TAI and greatly reduced the risk for culling. Ceftiofur is used for the treatment of mastitis, laminitis, and respiratory diseases (Zwald et al., 2004); therefore, one reason for our positive findings regarding this therapy could be that it minimizes the negative effect of any of these pathologies on the reproductive performance of the cows. Therefore, this is the first study reporting the effect of ceftiofur on production interest variables using a negative control.

Some studies have assessed the effect of 3-d ceftiofur therapy (Drillich et al., 2001, 2007; Zhou et al., 2001;
Benzaquen et al., 2007), whereas others have evaluated a 5-d treatment (Smith et al., 1998; Chenault et al., 2004). Regarding the use of 3-d protocols, Zhou et al. (2001) reported that ceftiofur-treated cows (1 mg/kg) had higher cure rates (defined as remission of fever and absence of vaginal discharge) than untreated control cows (56 vs. $29 \%$, respectively). Drillich et al. (2001) compared a 3 -d therapy with $1.1 \mathrm{mg} / \mathrm{kg}$ ceftiofur with an ampicillin plus cloxacillin intrauterine treatment and found similar cure rates (defined as remission of fever, $\sim 80 \%$ ). Drillich et al. (2007) also found similar cure rates (defined as remission of fever, $\sim 89 \%$ ) in cows receiving $1.1 \mathrm{mg} / \mathrm{kg}$ ceftiofur for $3 \mathrm{~d}$ (which was extended for 2 extra days if fever was present on treatment d 3) alone or in combination with flunixin meglumine. Regarding the use of 5-d protocols, Smith et al. (1998) found that $2 \mathrm{mg} / \mathrm{kg}$ ceftiofur was as effective as procaine penicillin $\mathrm{G}$ or procaine penicillin $\mathrm{G}$ plus intrauterine infusion of oxytetracycline for the treatment of metritis. Chenault et al. (2004) studied the effect of a 5 -d therapy with ceftiofur at 2 doses $(2.2$ and $1.1 \mathrm{mg} /$ $\mathrm{kg}$ ) with an untreated control and found cure rates (defined as remission of fever and absence of a fetid vaginal discharge) of 77,65 , and $62 \%$, respectively, $14 \mathrm{~d}$ after initial treatment. Unfortunately, to our knowledge, no published clinical trial has compared the effects of a 3 -d versus 5 -d therapy with ceftiofur for the treatment of metritis. Therefore, the lack of response to ceftiofur treatment in the current study might be explained in part by the treatment duration ( $3 \mathrm{~d}$ instead of $5 \mathrm{~d}$ ).

\section{Self-Cure Rate}

We found that the likelihood of having a normal VD (indicative of cure rate of metritis) increased $2.6 \%$ for every day of increase postpartum. As the effect of time on cure rate could be considered as an indicative of self-cure of metritis, this would be the first study to report an objective measure of the relationship between postpartum time and cure rate in dairy cows with metritis. We found that cows with clinical metritis have twice the odds for having a normal VD compared with those with puerperal metritis. The fact that cows having clinical metritis had a greater chance for cure than herdmates having puerperal metritis is expected on the basis that the latter is a life-threatening entity accompanied by systemic signs of illness (i.e., fever and depression), whereas the former is restricted to the uterus (Sheldon et al., 2006).

\section{CONCLUSIONS}

A deeper prepartum negative energy balance and calving problems were associated with an increased risk 
for metritis. Clinical metritis and puerperal metritis were associated with lower milk yield in early lactation. Puerperal metritis was related to lower early pregnancy rate and extended calving to conception interval. A 3-d therapy with ceftiofur was not associated with cure rate but was related to increased pregnancy rate at TAI and reduced risk for reproductive culling. Cure rate of metritis increased $2.6 \%$ per day of increase during the postpartum period and was double when the metritic cow was not febrile.

\section{ACKNOWLEDGMENTS}

This study was financed by a grant to R.L.S. (V11/134, Proyecto de Incentivos, Universidad Nacional de La Plata). The authors thank the farm owner and personnel for their support.

\section{REFERENCES}

Allison, P. D. 1999. Logistic Regression Using SAS: Theory and Application. SAS Institute Inc., Cary, NC.

Becú-Villalobos, D., I. García-Tornadú, G. Shroeder, E. E. Salado, G. Gagliostro, C. Delavaud, Y. Chilliard, and I. M. Lacau-Mengido. 2007. Effect of fat supplementation on leptin, insulin-like growth factor I, growth hormone, and insulin in cattle. Can. J. Vet. Res. $71: 218-225$.

Bell, M. J., and D. J. Roberts. 2007. The impact of uterine infection on a dairy cow's performance. Theriogenology 68:1074-1079.

Benzaquen, M. E., C. A. Risco, L. F. Archbald, P. Melendez, M. J. Thatcher, and W. W. Thatcher. 2007. Rectal temperature, calving-related factors, and the incidence of puerperal metritis in postpartum dairy cows. J. Dairy Sci. 90:2804-2814.

BonDurant, R. H. 1999. Inflammation in the bovine female reproductive tract. J. Anim. Sci. 77:101-110.

Bruun, J., A. K. Ersbøll, and L. Alban. 2002. Risk factors for metritis in Danish dairy cows. Prev. Vet. Med. 54:179-190.

Burfeind, O., M. A. G. von Keyserlingk, D. M. Weary, D. M. Veira, and W. Heuwieser. 2010. Short communication: Repeatability of measures of rectal temperature in dairy cows. J. Dairy Sci. 93:624-627.

Chenault, J. R., J. F. McAllister, S. T. Chester, K. J. Dame, F. M. Kausche, and E. J. Robb. 2004. Efficacy of ceftiofur hydrochloride sterile suspension administered parenterally for the treatment of acute postpartum metritis in dairy cows. J. Am. Vet. Med. Assoc. 224:1634-1639.

Correa, M. T., H. Erb, and J. Scarlett. 1993. Path analysis for seven postpartum disorders of Holstein cows. J. Dairy Sci. 76:13051312.

Delavaud, C., A. Ferlay, Y. Faulconnier, F. Bocquier, G. Kann, and Y. Chilliard. 2002. Plasma leptin concentration in adult cattle: Effects of breed, adiposity, feeding level, and meal intake. J. Anim. Sci. 80:1317-1328.

Díaz-Torga, G. S., M. E. Mejía, A. González-Iglesias, N. Formía, D. Becú-Villalobos, and I. M. Lacau-Mengido. 2001. Metabolic cues for puberty onset in free grazing Holstein heifers naturally infected with nematodes. Theriogenology 56:111-122.

Drillich, M., O. Beetz, A. Pfutzner, M. Sabin, H. J. Sabin, and P. Kutzer. 2001. Evaluation of a systemic antibiotic treatment of toxic puerperal metritis in dairy reproductive cows. J. Dairy Sci. 84:2010-2017.

Drillich, M., D. Voigt, D. Forderung, and W. Heuwieser. 2007. Treatment of acute puerperal metritis with flunixin meglumine in addition to antibiotic treatment. J. Dairy Sci. 90:3758-3763.
Dubuc, J., T. F. Duffield, K. E. Leslie, J. S. Walton, and S. J. LeBlanc. 2010. Risk factors for postpartum uterine diseases in dairy cows. J. Dairy Sci. 93:5764-5771.

Dubuc, J., T. F. Duffield, K. E. Leslie, J. S. Walton, and S. J. LeBlanc. 2011. Effects of postpartum uterine diseases on milk production and culling in dairy cows. J. Dairy Sci. 94:1339-1346.

Edmonson, A. J., I. J. Lean, L. D. Weaver, T. Farve, and G. Webster. 1989. A body condition scoring chart for Holstein dairy cows. J Dairy Sci. 72:68-78.

Ferguson, J. D., D. T. Galligan, and N. Thomsen. 1994. Principal descriptors of body condition score in Holstein cows. J. Dairy Sci. 77:2695-2703.

Fourichon, C., H. Seegers, N. Bareille, and F. Beaudeau. 1999. Effects of disease on milk production in the dairy cow: A review. Prev. Vet. Med. 41:1-35.

Fourichon, C., H. Seegers, and X. Malher. 2000. Effect of disease on reproduction in the dairy cow: A meta-analysis. Theriogenology 53:1729-1759

Greiner, M., D. Pfeiffer, and R. D. Smith. 2000. Principles and practical application of the receiver-operating characteristic analysis for diagnostic tests. Prev. Vet. Med. 45:23-41.

Gröhn, Y. T., H. N. Erb, C. E. McCulloch, and H. S. Saloniemi. 1990. Epidemiology of reproductive disorders in dairy cattle: Associations among host characteristics, disease and production. Prev Vet. Med. 8:25-39.

Ghavi Hossein-Zadeh, N., and M. Ardalan. 2011. Cow-specific risk factors for retained placenta, metritis and clinical mastitis in Holstein cows. Vet. Res. Commun. 35:345-354.

Huzzey, J. M., D. M. Veira, D. M. Weary, and M. A. G. v. Keyserlingk. 2007. Prepartum behavior and dry matter intake identify dairy cows at risk for metritis. J. Dairy Sci. 90:3220-3233.

Igono, M. O., G. Bjotvedt, and H. T. Sanford-Crane. 1992. Environmental profile and critical temperature effects on milk production of Holstein cows in desert climate. Int. J. Biometeorol. 36:77-87.

Kaneene, J. B., and R. Miller. 1995. Risk factors for metritis in Michigan dairy cattle using herd- and cow-based modelling approaches. Prev. Vet. Med. 23:183-200.

Kristula, M., B. I. Smith, and A. Simeone. 2001. The use of daily postpartum rectal temperatures to select dairy cows for treatment with systemic antibiotics. Bovine Pract. 35:117-125.

Lacau-Mengido, I. M., M. E. Mejıa, G. S. Díaz-Torga, A. GonzalezIglesias, N. Formia, C. Libertun, and D. Becu-Villalobos. 2000. Endocrine studies in ivermectin-treated heifers from birth to puberty. J. Anim. Sci. 78:817-824.

LeBlanc, S. J. 2008. Postpartum uterine disease and dairy herd reproductive performance: A review. Vet. J. 176:102-114.

Littell, R. C., W. W. Stroup, and R. J. Freund. 2002. SAS for Linear Models. 4th ed. SAS Institute Inc., Cary, NC.

Mateus, L., L. L. da Costa, F. Bernardo, and J. R. Silva. 2002. Influence of puerperal uterine infection on uterine involution and postpartum ovarian activity in dairy cows. Reprod. Domest. Anim. $37: 31-35$.

Mejía, M. E., and I. M. Lacau-Mengido. 2004. Endometritis treatment with a $\mathrm{PGF}_{2 \alpha}$ analog does not improve reproductive performance in a large dairy herd in Argentina. Theriogenology 63:1266-1276.

NRC. 2001. Nutrient Requirements of Dairy Cattle. 7th rev. ed. Natl Acad. Sci., Washington, DC.

Ospina, P. A., D. V. Nydam, T. Stokol, and T. R. Overton. 2010. Evaluation of nonesterified fatty acids and $\beta$-hydroxybutyrate in transition dairy cattle in the northeast United States: Critical thresholds for prediction of clinical diseases. J. Dairy Sci. 93:546-554.

Rajala, P. J., and Y. T. Grohn. 1998. Effects of dystocia, retained placenta, and metritis on milk yield in dairy cows. J. Dairy Sci. $81: 3172-3181$

SAS Institute. 2003. SAS/STAT Software for Windows 9.1. SAS Institute Inc., Cary, NC.

Sheldon, I. M., and H. Dobson. 2004. Postpartum uterine health in cattle. Anim. Reprod. Sci. 82-83:295-306.

Sheldon, I. M., G. S. Lewis, S. LeBlanc, and R. O. Gilbert. 2006. Defining postpartum uterine disease in cattle. Theriogenology 65:1516-1530. 
Sheldon, I. M., D. E. Noakes, A. N. Rycroft, D. U. Pfeiffer, and H. Dobson. 2002. Influence of uterine bacterial contamination after parturition on ovarian dominant follicle selection and follicle growth and function in cattle. Reproduction 123:837-845.

Smith, B. I., G. A. Donovan, C. A. Risco, R. Littell, C. Young, and L. H. Stanker. 1998. Comparison of various antibiotic treatments for cows diagnosed with toxic puerperal metritis. J. Dairy Sci. 81:1555-1562.

Soto, P., R. P. Natzke, and P. J. Hansen. 2003. Actions of tumor necrosis factor- $\alpha$ on oocyte maturation and embryonic development in cattle. Am. J. Reprod. Immunol. 50:380-388.

Swets, J. A. 1988. Measuring the accuracy of diagnostic systems. Science 240:1285-1293.

Systat. 2006. Sigmaplot User's Guide, version 10.0. Systat Software Inc., Chicago, IL.

Thrusfield, M., C. Ortega, I. de Blas, J. P. Noordhuizen, and K. Frankena. 2001. Win EPISCOPE 2.0: Improved epidemiological software for veterinary medicine. Vet. Rec. 148:567-572.

Urton, G., M. A. G. v. Keyserlingk, and D. M. Weary. 2005. Feeding behavior identifies dairy cows at risk for metritis. J. Dairy Sci. 88:2843-2849.
Wenz, J. R., D. A. Moore, and R. Kasimanickam. 2011. Factors associated with the rectal temperature of Holstein dairy cows during the first 10 days in milk. J. Dairy Sci. 94:1864-1872.

Williams, E. J., D. P. Fischer, D. U. Pfeiffer, G. C. England, D. E. Noakes, H. Dobson, and I. M. Sheldon. 2005. Clinical evaluation of postpartum vaginal mucus reflects uterine bacterial infection and the inflammatory response to endometritis in cattle. Theriogenology $63: 102-117$.

Wittrock, J. M., K. L. Proudfoot, D. M. Weary, and M. A. G. von Keyserlingk. 2011. Metritis affects milk production and cull rate of Holstein multiparous and primiparous dairy cows differently. J. Dairy Sci. 94:2408-2412.

Zhou, C., J. F. Boucher, K. J. Dame, M. Moreira, R. Graham, J. Nantel, S. Zuidorf, L. Arfi, R. Flores, G. Neubauer, and J. Olson. 2001. Multilocation trial of ceftiofur for treatment of postpartum cows with fever. J. Am. Vet. Med. Assoc. 219:805-808.

Zwald, A. G., P. L. Ruegg, J. B. Kaneene, L. D. Warnick, S. J. Wells, C. Fossler, and L. W. Halbert. 2004. Management practices and reported antimicrobial usage on conventional and organic dairy farms. J. Dairy Sci. 87:191-201. 